\title{
A modified open omental plugging of peptic ulcer perforation in a mission hospital, Northwestern Cameroon
}

\author{
Bamidele Johnson Alegbeleye* \\ Department of Surgery, St Elizabeth Catholic General Hospital, Shisong, Cameroon
}

\begin{abstract}
Background: Perforated peptic ulcer disease is a common cause of emergency surgical admission with potential risk of grave complications. Management is often by surgical closure. The age-long controversy had been whether omentoplasty or omental patch is necessary or not? This study therefore brings to the fore the patterns of presentation and methods of management of perforated peptic ulcer as well as the outcome, in a resource-constrained mission hospital, Northwestern Cameroon.

Methods: Retrospective cross-sectional study of patients with perforated peptic ulcer disease seen at St Elizabeth Catholic General Hospital, Shisong, Northwestern Cameroon over a three-year period from January 2016 to December 2018. Patients' records were reviewed for socio-demographics, probable risk factors, duration of disease, type of surgery and complications. Data obtained was analyzed using SPSS 22.0.

Result: Eighty-eight patients were analyzed. The mean age was (number; $n=38$ years \pm SD 12.4 years). There were ( $n=64 ; 72.7 \%)$ males out of which ( $n=58 ; 65.9 \%)$ survived and $(\mathrm{n}=24 ; 27.3 \%)$ females out of which $(\mathrm{n}=20 ; 22.7 \%)$ survived and this difference was statistically insignificant $(\mathrm{p}>0.05)$. The Male: Female ratio was 3.0: 1 . Mean age of survivors was 37.4 years and 43.7 years in those who expired. Farmers constituted the single largest group $(\mathrm{n}=38 ; 43.18 \%)$ followed by artisans $(\mathrm{n}=14 ; 15.70 \%)$, NSAIDs abuse $(\mathrm{n}=44)$, previous peptic ulcer disease $(\mathrm{n}=52)$ and no prior dyspeptic symptoms $(\mathrm{n}=36)$ constituted $50 \%, 60 \%$ and $40 \%$ respectively of cases. The age range was between 16 years and 74 years (The duration of symptoms before presentation ranged from 1 to 7 days; Fifty-two (n=52; 59\%) patients had perforated duodenal ulcer while thirty-six $(n=36 ; 41 \%)$ patients had perforated gastric ulcer. The preferred method of repair was simple closure of the edges with omental reinforcement in $(n=58 ; 65.9 \%)$ patients. The classical Graham's omentoplasty in $(n=20 ; 23 \%)$, and simple closure mainly in $(n=10 ; 11.6 \%)$; we had three $(n=3$; $3.4 \%)$ failed repair and ten $(n=10 ; 11.4 \%)$ mortalities. The presence of shock and sepsis is the single most important predictor of morbidity and mortality.
\end{abstract}

Conclusion: Surgery for perforated peptic ulcer still is a subject of debate despite more than an era of published expertise. Our patients present very late and, in most cases, following abuse of local herbal preparation and Non-steroidal anti-inflammatory drugs. The presence of shock and sepsis is the single most important predictor of morbidity and mortality. Credence is being laid on the pragmatic surgical intervention with modified Graham's omentoplasty in addition to broad spectrum antibiotics and $\mathrm{H}$. pylori eradication therapy is still highly beneficial in common practice. Health education to improve early health seeking habit is mandatory.

\section{Introduction}

Acute perforated peptic ulcer (PPU) is one of the commonest indications of emergency surgical admissions globally and accounts for more than $70 \%$ of deaths associated with peptic ulcer disease (PUD) [1,2]. Gastro-duodenal perforations vary in pattern from one geographical area to another $[1,3,4]$. Bekele et al. reported that duodenal perforations were more common than gastric perforations in Ethiopia and that PPU were more common in the youth (mean age of 33.4 years) $[1,3,4]$. In another report by Dongo et al. in Nigeria reported that PPU were more commonly seen in gastric ulcers and often affected an older population (mean age of 49.99 years) [3-5].

Historically, the first clinical description of a perforated peptic ulcer was on an autopsy done on the body of King Charles daughter, Henriette Anne, who died suddenly in 1670 (at 26 years of age) [1,57]. John Mikulicz (1850-1905), often credited to be the first surgeon who closed a perforated peptic ulcer (PPU) by simple closure, said: “ Every doctor, faced with perforated duodenal ulcer of the stomach or intestine, must consider opening the abdomen, sewing up the hole and averting a possible inflammation by careful cleansing of the abdominal cavity" [1,6-11]. This principle of treatment still applies in modern surgery today. Since then several notable people have succumbed to this illness over the years [1,7-11].
PUD remains a major health concern to clinicians globally in view of its attendant high morbidity, mortality and economic loss [12,13]. An estimated 5 million adults suffer annually from PUD and 500,000 new cases with 4 million recurrences are reported each year in the United States of America [12-14]. The incidence of PUD has fallen in recent years globally [15-17]. The development of new drugs for the treatment of PUD, better knowledge about its etiology, improvement in endoscopic facilities and eradication of Helicobacter pylori or H. pylori have contributed significantly to reducing the incidence of PUD and its complications $[12,15,18]$.

The pathogenesis of PUD is considered as representing a complex scenario involving an imbalance between defensive (mucusbicarbonate layer, prostaglandins, cellular renovation, and blood flow) and aggressive factors (hydrochloric acid, pepsin, ethanol, bile salts, some medications, etc.) [19-22]. In recent years, Helicobacter Pylori

${ }^{*}$ Correspondence to: Bamidele Johnson Alegbeleye, Department of Surgery, St Elizabeth Catholic General Hospital, Shisong, Cameroon, Tel: +237-670628857; E-mail: drbalegbeleye@gmail.com

Key words: helicobacter pylori, perforated peptic ulcers, simple closure with omentoplasty, cameroon

Received: April 02, 2019; Accepted: April 26, 2019; Published: May 02, 2019 
infection and abuse of non-steroidal anti-inflammatory drugs NSAIDs and gastric cancer have been identified as the main causes of peptic ulcer [19-27]. Alcoholics and smokers are at higher risk [22,27-30]. $H$. pylori infection has come to play a pivotal role in the etiopathogenesis of the disease $[22,23,31]$, and its eradication is associated with better prognosis $[22,23,31,32]$.

Management of PPU is quite challenging as patients present late; with septicemia, fluid and electrolyte derangements, shock and/or systemic inflammatory response syndrome. Three decades of advances in drug treatment of PUD has led to less need of elective surgery $[15,23]$. Surprisingly enough, treatment has not changed much since, still consisting of primary closure of the perforation by a single stitch suture and a convenient tag of adjacent omentum on top of this [19,3336]. Although this therapy sounds very simple PPU still remains a dangerous surgical condition, associated with high morbidity and mortality, not to be underestimated [19,37].

Following the diagnosis of PPU, there are a few different therapeutic options to be taken into consideration [19,38]. Firstly, there is need to evaluate the patient to determine suitability for surgery or consider for conservative treatment instead. Then the critical decision when surgery is indicated; is to consider whether simple closure with or without omentoplasty is sufficient. In recent time, the operation can be performed laparoscopically and there are risk factors that could make laparotomy a safer option $[19,38,39]$. The definitive operation for PPU is performed by few surgeons. Delay in diagnosis and initiation of surgical treatment of PPU has been reported to be associated with high morbidity and mortality postoperatively $[12,22,32,40]$.

The study becomes very paramount because there has not been any of such published reports on the surgical management of PPU in our local environment despite increase in the number of admissions of this condition. This study therefore brings to the fore the patterns of presentation and methods of management of PPU as well as the outcome, in a rural community, Northwestern Cameroon.

\section{Patients and methods}

\section{Study design and setting}

This retrospective cross-sectional study was conducted in department of surgery at St Elizabeth Catholic General Hospital, Shisong, Northwestern Cameroon over a three-year period from January 2016 to December 2018. The hospital is a 250-bedded mission hospital in Shisong - Kumbo, a rural community in Northwestern region of Cameroon which is located at about 100 kilometers from the regional Headquarter city of Bamenda. The hospital serves principally as referral center to an estimated five million people in the sub-region.

\section{Study population and procedure}

The study population consists of all patients admitted with intraoperative diagnosis of PPU. The exclusion criteria were the following:

i. All the other causes of peritonitis such as ruptured appendix, traumatic perforations, tuberculosis enteric perforations, etc., were excluded from the study.

ii. All patients with suspected peritonitis due to perforated peptic ulcer disease for whom a laparotomy was not performed.

iii. All patients whose case file did not contain follow-up data.

A pre-validated proforma was used for the collection of patients' data which included patient demographics, site and size of perforation, amount of pyoperitoneum, interval before presentation, and type of surgery performed as well as treatment and outcome. The diagnosis of perforated peptic ulcer was made on clinical grounds which was confirmed at laparotomy. Pre-operatively, the patients were resuscitated with intravenous fluids and had baseline biochemical and hematological investigations done. Erect and chest or lateral decubitus radiographs and abdominal ultrasound scan were carried out. Computerized tomographic (CT) scan was unavailable here during the study period. All patients were catheterized and had nasogastric suction. Surgery was performed via a midline supraumbilical incision after adequate resuscitation. Simple closure or omentoplasty was carried out with copious saline peritoneal lavage. The ulcer edge was excised for histology routinely. A drain was usually left in Morrison's pouch which was routinely removed on the seventh post-operative days. All patients received triple regime antibiotics for 14 days for $H$. pylori eradication. In addition, number of days spent in the post-operative period before discharge and occurrence of any post-operative complications were also reviewed. Note was also made of any re-operation. The patient's take-home medications, duration of their follow-up, any long-term complications and post-operative endoscopic findings after discharge were also noted.

\section{Statistical analysis}

All data were entered in an excel database (Excel 2007, Microsoft corporation ${ }^{\circ}$ ) and analyzed using the Statistical Package for the Social Sciences (SPSS) version 22 (IBM Corp, Armonk, NY, USA). Absolute numbers and simple percentages were used to describe categorical variables. Similarly, quantitative variables were described using measures of central tendency mean and measures of dispersion such as range or standard deviation as appropriate. Descriptive statistics was used in the form of bar chart and pie-chart etc. Student t-test was used for analysis of parameters and chi-square test for the assessment of different categorical data. The mean differences between groups were compared by Student's t-test; otherwise, Mann-Whitney U test was applied for comparisons of the median values. Nominal data were analyzed by Pearson's X2 or Fisher's exact test, where applicable. To evaluate the risk factors influencing morbidity and mortality, multivariate logistic regression test was used after adjustment for all possible confounding factors. Odds ratio (OR) was calculated for every variable. A value of $\mathrm{p}<0.05$ for all variables was considered significant.

Ethical Considerations: Ethical approval was obtained from the Institutional Ethical Committee. Confidentiality was ensured by not writing the names of patients on the proforma.

Reporting: The STROBE/STROCSS guidelines were used in reporting this study $[41,42]$.

\section{Results}

\section{Patient's characteristics}

A total number of 106 patients were treated for PPU within the study period only 88 had complete data for the review. The age range was between 16 years and 74 years (Figure 1). The incidence of perforation was highest in the age group of 30-39 years $(22.3 \%)$. The mean age was $(\mathrm{n}=38$ years \pm SD 12.4 years). Mean age of survivors was $(\mathrm{n}=37.4$ years $)$ and $(n=43.7$ years) in those who expired. There were $(n=64 ; 72.7 \%)$ males out of which $(n=58 ; 65.9 \%)$ survived and $(n=24 ; 27.3 \%)$ females out of which $(n=20 ; 22.7 \%)$ survived and this difference was statistically insignificant $(\mathrm{p}>0.05)$. Therefore, giving a Male: Female ratio of 3.0: 1 


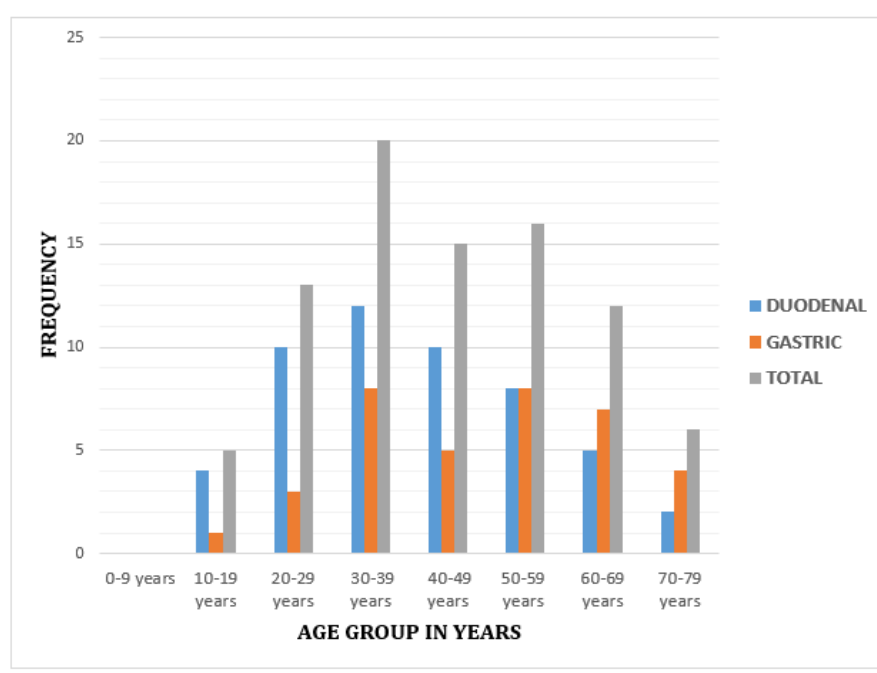

Figure 1. Age distribution and site of perforation

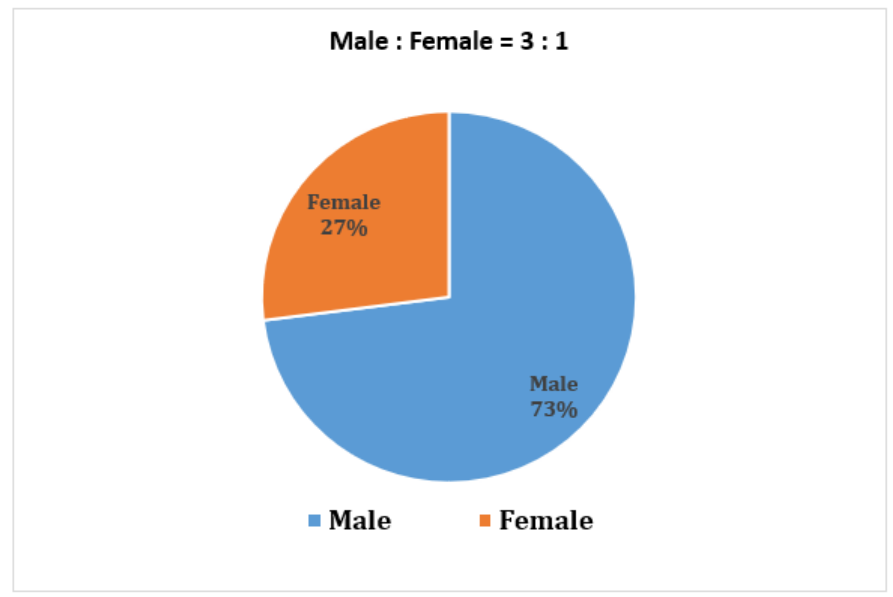

Figure 2. Gender distribution

(Figure 2). The frequency of patients with perforated duodenal ulcer were $(n=52 ; 59 \%)$ while those patients who had perforated gastric ulcer were $(n=36 ; 41 \%)$, giving a duodenal to gastric ulcer ratio of $1.44: 1$. The duration of symptoms before presentation ranged from 2 to 7 days; A total of $(n=26 ; 29.55 \%)$ patients presented within $24 \mathrm{~h}$ of onset of symptoms, $(n=34 ; 38.64 \%)$ patients presented between 24 and $48 \mathrm{~h}$ of onset of symptoms; while $(\mathrm{n}=28 ; 31.82 \%)$ presented after $48 \mathrm{~h}$ of onset. Ten $(\mathrm{n}=10 ; 11.4 \%)$ of the patients had a prior diagnosis of their ulcer by an upper gastro-intestinal endoscopy (UGIE) before presentation. Patients with past treatment for PUD but, with inadequate or no medical treatment were $(n=52 ; 60 \%)$. They were on routine use of antiulcer medications within the last six months before perforation. The remainder, $(n=36 ; 40 \%)$ cases presented for the first time with perforation, with no prior treatment for PUD. All the patients in this series had a single perforation. The mean age for the duodenal ulcer perforation was $(n=31.25$ years \pm SD 10.02 years $)$. The mean age for gastric ulcer perforation was ( $\mathrm{n}=49.23$ years \pm SD 12.16 years).

Furthermore, majority of the patients were from the lower socioeconomic groups. Farmers constituted the single largest group $(\mathrm{n}=38 ; 43.18 \%)$; Artisans $(\mathrm{n}=14 ; 15.70 \%)$, Traders $(\mathrm{n}=10 ; 11.6 \%)$; Teachers $(n=8 ; 9.7 \%)$; Students $(n=7 ; 7.95 \%)$ and others $(n=11 ; 12.5 \%)$ (Table 1).

\section{Characteristics of the perforated peptic ulcer}

The patients presented with symptoms like sudden severe upper abdominal pain in all $(\mathrm{n}=88 ; 100 \%)$ patients and nausea and vomiting in $(n=80 ; 90 \%)$ patients. Fever occurred in only $(n=20 ; 22.72 \%)$ patients, abdominal distension in $(\mathrm{n}=72 ; 81.81 \%)$ patients. Abdominal tenderness was seen in $(\mathrm{n}=87 ; 98.7 \%)$ patients and clinical signs of peritonitis like abdominal rigidity in all 80 (91\%) patients (Table 2). The patients came with symptoms, which occurred 1-4 days before presentation.

The notable risk factor was the free abuse of herbal concoction (admixture of local gin, spices, roots and bitters) for body pains. Most the patients took this mixture, at one time or the other. Some even took it following the sudden onset of abdominal pains. Risk factors identified include NSAID use in $(n=44 ; 50 \%)$ cases, including the youngest patient, ingestion of herbal concoctions in $(n=54 ; 61 \%)$, and smoking in $(n=20 ; 23 \%)$.

The sizes of perforation ranged in $<1 \mathrm{~cm},(\mathrm{n}=44 ; 50 \%)$; between 1 and $2 \mathrm{~cm},(\mathrm{n}=30 ; 34.5 \%)$; and $>2 \mathrm{~cm},(\mathrm{n}=14 ; 15.5 \%)$. The quantity of pyoperitoneum at laparotomy ranged between $<1$ Liter: $(n=24$; 27.30\%); 1 and 2 Liters: $(n=44 ; 50 \%)$, and $>2$ Liters: $(n=20 ; 22.70 \%)$. The preferred method of repair was simple closure of the edges with omental reinforcement in $(n=58 ; 65.9 \%)$ patients (Table 3$)$. The rest had the classical Graham's omental patch repair (omentoplasty) in $(n=20$; $23 \%)$, and simple closure mainly in $(\mathrm{n}=10 ; 11.6 \%)$; while three patients with large ulcer perforation, in addition to simple closure and lavage had anterocolic gastro-jejunostomy to divert gastric secretion away from the repaired perforation (Table 3 ). None of the patients had a definitive anti-ulcer surgery in the form of vagotomy and a drainage procedure. There were 5 reoperations, 3 for leakage of repair and 2 for intra-abdominal collections with repair intact. None of the samples sent for histology revealed any malignancy. In the eventual outcome, postoperative complications were seen in 60 patients. The complications were surgical site infection in $(n=23 ; 26.14 \%)$ patients, which was the most common complications and closely followed by wound dehiscence $(n=15,17.04 \%)$. In total, $(n=14 ; 15.90 \%)$ patients developed chest infection, $(n=5 ; 5.68 \%)$ complicated with enterocutaneous fistula, $(n=12 ; 13.6 \%)$ patients developed septicemia in the post-operative period. Depending upon their symptoms at each visit, patients were classified according to Visick grading system as follows: Visick grade I: $(n=48 ; 82.75 \%)$ patients, Visick grade II: $(n=8 ; 13.8 \%)$ patients, Visick grade III and IV: $(n=2 ; 3.44 \%)$ patients each respectively. One

Table 1. Occupation

\begin{tabular}{|c|c|c|}
\hline Occupation & Number of patients & Percentage \\
\hline Farmers & 38 & 43.18 \\
\hline Artisans & 14 & 15.70 \\
\hline Traders & 10 & 11.60 \\
\hline Teachers & 8 & 9.07 \\
\hline Students & 7 & 7.95 \\
\hline Others & 11 & 12.5 \\
\hline Total & $\mathbf{8 8}$ & $\mathbf{1 0 0}$ \\
\hline
\end{tabular}

Table 2. Clinical presentation

\begin{tabular}{|c|c|c|}
\hline Clinical presentation & Number of patients & Percentage \\
\hline Pain & 88 & 100.0 \\
\hline Nausea \& Vomiting & 80 & 90.00 \\
\hline Fever & 20 & 22.72 \\
\hline Constipation & 54 & 61.36 \\
\hline Air under diaphragm & 80 & 90.00 \\
\hline Abdominal distention & 72 & 81.81 \\
\hline Abdominal rigidity & 80 & 91.0 \\
\hline
\end{tabular}


of patients in Visick grade IV presented with re-perforation about eight months post first laparotomy which necessitated re-operation. Seventyeight patients $(n=78 ; 88.6 \%)$ were discharged home and followed up for 6 to 12 months after surgery and there were $(n=10)$ deaths indicating $11.4 \%$ mortality rate in all.

In the multivariate logistic regression analysis, age above 60 , presence of a concomitant disease, herbal concortion and NSAID use, simple closure as well as APACHE II score above 11 and MPI above 26 were found to be independent risk factors influencing morbidity (Table 4). From Table 5 in the multivariate logistic regression analysis, age above 60, time to presentation, APACHE II score above 11 and MPI above 26 were found to be independent risk factors influencing mortality. The presence of shock and sepsis is the single most important predictor of morbidity and mortality.

Table 3. Method of repair
\begin{tabular}{|c|c|c|}
\hline Method of repair & Number of patients & Percentage \\
\hline Simple Closure & 10 & 11.60 \\
\hline $\begin{array}{c}\text { Simple Closure with omental } \\
\text { reinforcement }\end{array}$ & 58 & 65.40 \\
\hline $\begin{array}{c}\text { Graham's omental Patch } \\
\text { Repair }\end{array}$ & 20 & 23.00 \\
\hline Total & $\mathbf{8 8}$ & $\mathbf{1 0 0}$ \\
\hline
\end{tabular}

Table 4. Factors influencing morbidity on multivariate Logistic regression analysis

\begin{tabular}{|c|c|c|c|c|}
\hline Variable & $\begin{array}{c}\text { Group } \\
\text { without } \\
\text { morbidity } \\
(\mathrm{N}=62)\end{array}$ & $\begin{array}{l}\text { Group with } \\
\text { Morbidity } \\
\text { (N=26) }\end{array}$ & P-value & $\begin{array}{c}\text { Odds Ratio (95\% } \\
\text { Confidence Intervals- } \\
\text { CI ) }\end{array}$ \\
\hline \multicolumn{5}{|l|}{ Gender } \\
\hline Male & $44(70.96 \%)$ & $18(69.92 \%)$ & -- & 1.000 \\
\hline Female & $18(29.02 \%)$ & $08(30.77 \%)$ & 0.743 & $1.123(0.518-2.114)$ \\
\hline $\begin{array}{l}\text { Age in years } \\
(\text { Mean } \pm \text { SD) }\end{array}$ & $42 \pm \mathrm{SD} 10.62$ & $62 \pm \mathrm{SD} 11.21$ & $<0.001$ & $1.052(2.031-110.06)$ \\
\hline Co-morbidities & $24(38.71 \%)$ & $18(66.03 \%)$ & $<0.001$ & $3.608(1.843-5.869)$ \\
\hline \multicolumn{5}{|l|}{ Admission period } \\
\hline$<24$ hours & $48(74.50 \%)$ & $06(23.07 \%)$ & 0.484 & $0.541(1.874-2.346)$ \\
\hline$>24$ hours & $52(82.38 \%)$ & $05(19.23 \%)$ & 0.581 & $0.694(1.943-2.524)$ \\
\hline Shock & $05(25 \%)$ & $04(74.87 \%)$ & 0.853 & $0.476(0.125-5.623)$ \\
\hline NSAID use & $40(80.22 \%)$ & $21(100 \%)$ & $<0.001$ & $3.098(1.637-5.863)$ \\
\hline $\begin{array}{l}\text { Herbal concortion } \\
\text { use }\end{array}$ & $56(87.45 \%)$ & $22(98 \%)$ & $<0.001$ & $2.942(1.812-4.216)$ \\
\hline $\begin{array}{l}\text { ASA score } \\
\text { (average range) }\end{array}$ & $01(1-4)$ & $03(1-5)$ & $<0.001)$ & NA \\
\hline $\begin{array}{l}\text { Free intra- } \\
\text { abdominal air on } \\
\text { AXR }\end{array}$ & $78(80.32 \%)$ & $18(20.23 \%)$ & 0.962 & $1.527(0.383-3.183)$ \\
\hline $\begin{array}{l}\text { Perforation } \\
\text { diameter }(\mathrm{mm} \\
\text { range) }\end{array}$ & $05(02-100)$ & $10(2-50)$ & 0.946 & $1.021(0.987-1.869)$ \\
\hline \multicolumn{5}{|l|}{ APACHE II } \\
\hline$<11$ & $68(94.12 \%)$ & $07(6.23 \%)$ & $<0.001$ & $1.684(1.482-2.112)$ \\
\hline$>11$ & $16(32.44 \%)$ & $20(67.54 \%)$ & & \\
\hline \multicolumn{5}{|l|}{ MPI } \\
\hline$<26$ & $72(92.22 \%)$ & $10(7.84 \%)$ & $<0.001$ & $2.121(1.778-3.473)$ \\
\hline$>26$ & $04(11.45 \%)$ & $01(5.13 \%)$ & & \\
\hline \multicolumn{5}{|l|}{ Type of operation } \\
\hline Simple closure & $08(72.12 \%)$ & $02(90.76 \%)$ & 1.000 & $0.969(0.305-3.104)$ \\
\hline $\begin{array}{l}\text { Modified Graham's } \\
\text { technique }\end{array}$ & $48(56.23 \%)$ & $10(62.44 \%)$ & 0.886 & $0.725(1.984-3.045)$ \\
\hline $\begin{array}{l}\text { Classical Graham's } \\
\text { closure }\end{array}$ & $16(44.52 \%)$ & $4(59.35 \%)$ & 0.794 & $0.658(0.949-2.945)$ \\
\hline
\end{tabular}

SD: Standard Deviation; AXR: Plain Abdominal X-Ray; NSAID: Non-Steroidal AntiInflammatory Drugs; MPI: Mannheim Peritonitis Index; ASA: The American Society of Anesthesiologists Score; APACHE: Acute Physiology and Chronic Health Evaluation
Table 5. Factors influencing mortality on multivariate Logistic regression analysis

\begin{tabular}{|c|c|c|c|c|}
\hline Variable & $\begin{array}{c}\text { Group } \\
\text { without } \\
\text { morbidity } \\
(\mathrm{N}=62)\end{array}$ & $\begin{array}{c}\text { Group } \\
\text { with } \\
\text { Morbidity } \\
\text { (N=26) }\end{array}$ & P-value & $\begin{array}{c}\text { Odds } \\
\text { Ratio } \\
\text { (95\% confidence } \\
\text { intervals- } \text { CI })\end{array}$ \\
\hline \multicolumn{5}{|l|}{ Gender } \\
\hline Male & $40(70.96 \%)$ & $15(69.92 \%)$ & 0.089 & $1.402(1.121-4.255$ \\
\hline Female & $18(29.02 \%)$ & $08(30.77 \%)$ & 0.743 & $1.123(0.518-2.114)$ \\
\hline $\begin{array}{c}\text { AGE in years } \\
(\text { Mean } \pm \text { SD) }\end{array}$ & $\begin{array}{c}42 \pm \mathrm{SD} \\
10.62\end{array}$ & $\begin{array}{c}62 \pm \mathrm{SD} \\
11.21 \\
\end{array}$ & 0.219 & $1.052(1.031-1.061)$ \\
\hline Co-morbidities & $28(62.21 \%)$ & $17(37.85 \%)$ & 0.022 & $4.728(1.893-6.269)$ \\
\hline \multicolumn{5}{|l|}{ Admission period } \\
\hline$<24$ hours & $55(81.40 \%)$ & $08(12.58 \%)$ & 0.425 & $0.541(1.874-2.346)$ \\
\hline$>24$ hours & $47(72.38 \%)$ & $02(08.23 \%)$ & 0.026 & \\
\hline Shock & $05(25 \%)$ & $04(64.87 \%)$ & 0.253 & $0.476(0.199-4.429)$ \\
\hline NSAID use & $10(90.22 \%)$ & $4(70 \%)$ & 0.456 & $2.098(0.837-4.963)$ \\
\hline Herbal concortion use & $46(77.05 \%)$ & $11(88 \%)$ & 0.342 & $3.644(1.662-3.714)$ \\
\hline $\begin{array}{l}\text { ASA score } \\
\text { (average range) }\end{array}$ & $01(1-4)$ & $03(1-5)$ & 0.132 & NA \\
\hline $\begin{array}{l}\text { Free intra-abdominal air } \\
\text { on AXR }\end{array}$ & $78(80.32 \%)$ & $18(20.23 \%)$ & 0.784 & $2.737(0.283-3.715)$ \\
\hline $\begin{array}{l}\text { PERFORATION } \\
\text { DIAMETER (mm range) }\end{array}$ & $05(02-100)$ & $10(2-50)$ & 0.946 & $1.021(0.987-1.869)$ \\
\hline \multicolumn{5}{|l|}{ APACHE II } \\
\hline$<11$ & $49(78.32 \%)$ & $05(5.23 \%)$ & 0.058 & $1.684(1.482-2.112)$ \\
\hline$>11$ & $13(28.44 \%)$ & $22(55.54 \%)$ & & \\
\hline \multicolumn{5}{|l|}{ MPI } \\
\hline$<26$ & $78(88.62 \%)$ & $08(8.94 \%)$ & 0.008 & $3.121(1.778-3.473)$ \\
\hline$>26$ & $04(10.45 \%)$ & $02(6.13 \%)$ & & \\
\hline \multicolumn{5}{|l|}{ Type of operation } \\
\hline Simple closure & $09(52.12 \%)$ & $02(78.14 \%)$ & 0.427 & $1.469(1.705-4.204)$ \\
\hline $\begin{array}{l}\text { Modified Graham's } \\
\text { technique }\end{array}$ & $41(52.23 \%)$ & $11(58.44 \%)$ & 0.776 & $1.525(1.211-3.835)$ \\
\hline Classical Graham's closure & $11(34.32 \%)$ & $2(68.24 \%)$ & 0.884 & $1.959(1.649-4.244)$ \\
\hline
\end{tabular}

SD: Standard Deviation; AXR: Plain Abdominal X-Ray; NSAID: Non-Steroidal AntiInflammatory Drugs; MPI: Mannheim Peritonitis Index; ASA: The American Society of Anesthesiologists Score; APACHE: Acute Physiology and Chronic Health Evaluation

\section{Discussion}

In our series, PPU was highest in the age group of 30-39 years. The youngest patient was 16 years and the oldest was 74 years of age. More male patients tend to be affected than females, with a male to female ratio of 3.0 to 1 . This finding was similar to what obtained in other studies in the developing countries [15,43-45]. The authors found PPU to be very common in the fourth decade of life. They reasoned that this was due increased alcohol consumption amongst the males in this age group. Alcohol is ulcerogenic, causing increase in acid secretion and gastric mucosa damage. [15,43-45].

The patients' characteristic is also contrary to what is reported in developed countries where the majority of the patients are above 60 years with female preponderance. Majority of these elderly females in the western countries are on anti-ulcer drugs [12,46]. The male predominance in this age group in our setting may be attributed also to greater hardship, alcoholism, smoking of cigarette, and indiscriminate NSAIDs use. This finding is consistent with several other reports from Africa which confirm a male preponderance from a low $1.3: 1$ in Bugando, Tanzania $[5,47]$, to a high ratio of $8.3: 1$ in Techiman, Ghana $[3,48]$, and $14: 1$ in Ido Ekiti, Nigeria [3,49]. It is in sharp contrast to the common depiction in western series as a disease of the elderly female $[46,50]$.

Furthermore, we equally found the mean age for the duodenal ulcer perforation was $(n=31.25$ years \pm SD 10.02 years). The mean age 
for gastric ulcer perforation was: $(n=49.23$ years \pm SD 12.16 years $)$. More than $75 \%$ of all duodenal perforations occur before the age of 50 years $[12,51]$. The risk factors are attributed to the fact that majority of the patients being predominantly farmers and artisans freely abuse the consumption of herbal concoction (admixture of local gin, spices, roots and bitters) for body pains as well as Ibuprofen (NSAID) in some cases. This herbal concoction and NSAID have been implicated in the etiogenesis of peptic ulceration even in the pediatric age group previously $[12,51]$. NSAID inhibits prostaglandin synthesis so further reducing gastric mucosal blood flow [52]. There are several literature from other African studies which reveal a majority of duodenal perforation [53-55]. While we have no clear explanation for this changing epidemiological profile, we note that perforated peptic ulcers share similar pathogenesis especially with that resulting from $H$. pylori infestation [56] which is implicated in younger patients in the lower socioeconomic group [12,57]. Studies from Southern and Northern Nigeria confirm a high prevalence of $81.4 \%$ when using urease culture tests for antral biopsies and as high as over $90 \%$ with serological tests amongst dyspeptic patients $[12,58,59]$. Although determination testing for $H$. pylori was unavailable in our center during this study, all patients with perforated ulcers received eradication therapy for $H$. pylori.

In this study, a total of eighty-eight patients were operated over a three-year period giving an average of 29 cases annually. This is relatively low, and the figure is similar to what was reported by Schein et al and other authors [12,60-62], Mieny et al. [12,62] in South Africa also reported a low average of almost twenty-one cases annually. But this figure is slightly higher than those described in Enugu Nigeria and some Eastern as well as Southern African series [12,47,61]. These differences reflect differences in the rate of risk factors for PPU from one country to another $[12,47,61]$.

Moreover, in this series, $(n=52 ; 60 \%)$ patients had past treatment for PUD but, with inadequate or no medical treatment. They were on routine use of antiulcer medications within the last six months before perforation. The remainder, $(n=36 ; 40 \%)$ presented for the first time with perforation with no prior treatment for peptic ulcer disease. This finding is concordance with report of Nuhu et al in Nigeria who reported that $71 \%$ of cases had previous history of peptic ulcer disease [43]. In sharp contrast to other studies in many of these developing countries, which showed that the diagnosis of PUD is first made in several instances after perforation $[9,15,46,53]$.

In this present study the majority of patients (more than sixty percent) presented to the hospital 24 hours after of onset of symptoms. Everett et al $[63,64]$ in their study observed that majority of patients (68\%) presented within 24 hours of onset of symptoms. Limiting surgical delay is of paramount importance in treating patients with PPU $[63,65]$. In most rural communities of developing African countries like ours, there are numerous hurdles for patients with surgical needs, ranging from cultural perceptions of healthcare, travel distance as well as direct and hidden patient costs, to shortage of operating rooms, safe anesthesia, sterilization capacity, surgical instruments and surgeons $[63,66-69]$. Some of the treatment delays seen in this study may have been caused by beliefs in traditional treatments $[66,68]$, the lack of trained manpower in smaller clinics to properly diagnose and refer this condition earlier $[65,68]$, and inadequate finances to pay hospital bills $[32,66]$. These delays in care likely increase also the incidence and severity of postoperative complications, such as high rate of sepsis and metabolic derangement as well as death [66].

Determinants of Morbidity and Mortality: In agreement with several other studies we observed that based on the multivariate analysis; the risk factors for morbidity include age above 60 [70], delay in presentation over 24hours [71-73], the presence of shock on presentation [73-75], the presence of concomitant diseases in $[70,71,76,77]$, NSAID and Herbal use $[71,73,75]$ as well as perforation diameter was wider than $0.5 \mathrm{~cm}$ in PPU [78]. Billing et al. [79] specified that MPI was effective in the prediction of morbidity as seen in Table 4. Similarly, in our study, we determined that patients with an MPI above 26 and APACHE II score above 11 were at higher risk of developing morbidity (Table 4).

The factors influencing mortality in our patients were in accordance with publications reporting that the presence of shock at the time of presentation increased mortality, APACHE II score above 11 and MPI above $26[71,72,80]$ as shown in (Table 5).

\section{Diagnosis}

We made the diagnosis of PPU in this study from history and identification of free air under the diaphragm in plain chest and abdominal radiographs. The diagnosis was thereafter confirmed at laparotomy. From the current radiological techniques; $80-90 \%$ of cases were correctly diagnosed; other literature reported similar findings $[12,16,51]$. Recently, Computerized tomography (CT) scans with oral contrast are now considered the reliable method of detecting small pneumoperitoneum before surgery and the gold standard for the diagnosis of a perforation [12,54,81-83]. However, we relied on plain radiographs of the chest/ abdomen to establish the diagnosis of free intra-peritoneal air which was demonstrated in about $90 \%$ of cases in this series.

\section{Omentoplasty}

Historically, the age-long controversy had been whether omentoplasty or omental patch is necessary or not? Cellan-Jones [84] in 1929 published an article entitled 'a rapid method of treatment in perforated duodenal ulcers. The option of treatment at that time was, after excision of friable edges if indicated, the application of purse string sutures and on top an omental graft or plug otherwise referred to as omentoplasty [84]. An encountered problem was narrowing of the duodenum. To avoid this, he suggested omentoplasty without primary closure of the defect. His technique consisted of placing 4-6 sutures, selecting a long omental strand passing a fine suture through it, the tip of the strand is then anchored in the region of the perforation and finally the sutures are tied off [84]. Meanwhile, Graham in 1937 published his results with a free omental graft [85]. He placed three sutures with a piece of free omentum laid over these sutures, which are then tied. No attempt is made to actually close the perforation [85]. The omental graft provides the stimulus for fibrin formation. His approach has been the golden standard since [86]. Very often surgeons mention they used a Graham patch, but they actually mean they used the pedicled omental patch described by Cellan-Jones [84]. Other authors like Schein [85] could not have outlined it any clearer: 'Do not stitch the perforation but plug it with viable omentum and patch a perforated ulcer as much as you can, then you must resect if you cannot' [87].

From this series, the preferred method of repair was simple closure of the edges with omentum reinforcement in $(n=58 ; 65.9 \%)$ patients. The rest had Graham's omental patch repair in $(n=20 ; 23 \%)$, and simple closure only in $(n=10 ; 11.6 \%)$ of the cases (Table 3$)$. Mikulicz $[82,88]$ was the first to suture a perforated gastric ulcer. The current treatment of PPU is primary (simple) closure, with omentum reinforcement. The classical Graham patch technique, described by Graham in 1937 can be applied $[63,82]$. This series confirmed that there is no statistically 
significant difference considering the eventual postoperative outcome, and therefore laid credence to the fact that there is a gradual depart from the traditional classical Graham's omental patch as the sole method of repair and in agreement with other reports from the literature $[12,63,64]$. This method of closing the perforation not only by sutures but also with an omental plug reinforcement provides the sealing and tamponade effect of the omental plug described by several authors as the best treatment option $[12,63,64]$.

\section{Falciform ligament Patch}

One key challenging surgical moment is the repair of reperforation or leak of duodenal ulcer as was performed in this series in the three patients that had post-operative leak. In which the omentum had been completely "eaten up" that is became fibrotic and no longer available to the surgeon for repair, worst still the duodenum had become so edematous and simple closure was practically impossible. Then the evidence based available option of plugging the perforation was with the falciform ligament. This is usually done by freeing the distal attachment of the falciform ligament and then plugging it over the perforation and carefully closing the perforation with about 2-3 stitches using a size (2/0 or 0 -vicryl) suture tensionfree [89-91]. There has been paucity of literature on this approach by Surgeons worldwide. This formidable life-saving 'Falciform ligament Patch' can be performed open or laparoscopically and it's tagged "falciform ligament to the rescue" [88-90]. Some studies described falciform ligament as a better alternative than omentum regarding post-operative leak, ease of surgery, duration of surgery, and general outcome of the patient [89-91].

\section{Laparoscopic approach}

In a related development, there is a paradigm shift to minimal access laparoscopic surgery for the operative management of PPU in selected patients with reduced postoperative pain, wound infection and burst abdomen in centers where laparoscopic emergency surgery facilities are available with requisite laparoscopic suturing expertise $[19,50,92,93]$.

\section{Outcome}

We found that wound sepsis $(n=23 ; 26.14 \%)$ was the most common complications followed by wound dehiscence $(n=15$; $17.04 \%)$. In total, $(\mathrm{n}=14 ; 15.90 \%)$ patients developed chest infection, $(n=5 ; 5.68 \%)$ complicated with enterocutaneous fistula, $(n=12 ; 13.6 \%)$ patients developed septicemia in the post-operative period, and $(\mathrm{n}=10)$ patients ultimately died. Mortality rate was found to be $11.4 \%$ in this study. Everett et al. [63,64] observed chest infection in $27 \%$, wound infection in $16 \%$, wound dehiscence in $11 \%$, leak in $12 \%$, and a mortality rate of $23.5 \%$. SeungJin et al. $[63,94,95]$ found an overall 30 day mortality rate to be $3.17 \%$, while Kenneth et al. $[50,63]$ observed a mortality rate of $16.3 \%$. Ultimately, we had $(n=78 ; 88.63 \%)$ patients discharged home, all the patients were followed up for 6 to 12 months post-operatively.

Depending upon their symptoms at each visit, patients were classified according to Visick grading system [96] as follows: Visick grade I, $(\mathrm{n}=48 ; 82.75 \%)$ patients, Visick grade II, $(\mathrm{n}=8$; $13.8 \%)$ patients, Visick grade III and IV, $(\mathrm{n}=2 ; 3.44 \%)$ patients each respectively. One of patients $(n=1 ; 1.72 \%)$ in Visick grade IV presented with re-perforation about eight months post first laparotomy which necessitated re-operation.

\section{Limitations of the study}

Retrospective nature of the study could be marred by poor record keeping as noted in the incomplete data in less than $10 \%$ of the total patients managed.

1. Lack of Electronic Medical Record System in the hospital in the past years until January 2018 with resultant loss of data.

2. Delay in patients' presentation, and compounded by the on-going anglophone- crisis

3. Poverty, ignorance, false beliefs and insufficient health infrastructure, in the sub-region of Cameroon are amongst the lists of possible limitations of this study.

\section{Conclusion}

Surgery for PPU still is a subject of debate despite more than an era of published expertise and predominantly a disease of middle-aged men in our environment. Patients with old age, concomitant diseases, delay in presentation longer than 24 hours and, presence of shock at the time of presentation, and a perforation size wider than $0.5 \mathrm{~cm}$ diameter are at high risk for post-operative morbidity and mortality. MPI scoring system is reliable in predicting morbidity, while MPI and APACHE II in predicting mortality. The presence of shock and sepsis is the single most important predictor of morbidity and mortality. This series laid credence to the fact that there is a gradual depart from the traditional classical Graham's omental patch as the sole method of repair. We recommend a prospective study, preferable a multi-center one, to ascertain the epidemiology, risk and prognostic factors of the disease. Health education aimed at improving health care seeking habit of the population would be highly beneficial.

\section{Recommendations}

1. Full implementation of Electronic Medical Record System in our local hospitals in the sub-regions for a comprehensive data base will support improved future research on the disease.

2. There is an urgent public health concerted effort aimed at improving health care seeking habit of the population.

3. Educating the populace on early and prompt diagnosis, adequate resuscitation as well as early surgery in patients with perforated peptic ulcer disease to keep the morbidity and mortality low.

4. Patients who are misguided by false beliefs can be better educated by public enlightenment.

5. Effective government legislation on indiscriminate consumptions of herbal remedies, NSAIDs as well as another drug use.

6. It is imperative for prompt and early resolution of ongoing Anglophone crisis and in resource constrained setting as ours, an improvement of existing health infrastructure.

7. There is also a strong need for collaboration and integration of the Traditional medicine and Biomedical practices as advocated by the WHO; so as to harness the gains by all and sundry.

8. Functional health insurance for all citizens is mandatory.

9. Finally, we recommend a prospective study, preferable a multi-center one, to ascertain the epidemiology, risk and prognostic factors of the disease. 


\section{Declarations}

\section{Acknowledgements}

Not Applicable.

\section{Funding}

No record of funding for this clinical research study declared.

\section{Availability of data and materials}

Availability of data and materials confirmed by the author and available for review by the Editor-in-Chief of this journal.

\section{Disclosures}

The author has no disclosures.

\section{Authors' contributions}

BJA conceived of the study and participated in its design and coordination as well as helped to draft the manuscript; the author also read and approved the final manuscript.

\section{Ethics approval and consent to participate}

Ethical approval was obtained from the Institutional Ethical Committee. Confidentiality was ensured by not writing the names of patients on proforma. A copy of the written Approval is available for review by the Editor-in-Chief of this journal.

\section{Consent for publication}

This is a retrospective review and no direct human participants and there are no accompanying images. Confidentiality was ensured by not writing the names of patients on proforma. Clinical trial registered at Pan African Clinical Trial Registry (www.pactr.org) database with unique identification number-PACTR201903591178107.

\section{Competing interests}

The author declares that he has no competing interests.

\section{References}

1. Odula PO (2017) Omentoplasty in Perforated Peptic Ulcer Surgery: Is it Still the Gold Standard? Ann Afr Surg 14: 57-60.

2. Svanes C (2000) Trends in Perforated Peptic Ulcer: Incidence, Etiology, Treatment and Prognosis. World J Surg 24: 277-283. [Crossref]

3. Williams N, Bullstrode C, O'Connell P (2013) Stomach and Duodenum in Bailey and love's short Practice of surgery, CRC, London, UK.

4. Bekele A, Zemenfes D, Kassa S, Deneke A, Taye M, et al. (2017) Patterns and Seasonal Variations of perforated Peptic Ulcer Disease: Experience from Ethiopia. Ann Afr Surg 14: 86-91.

5. Dongo AE, Uhunmwagho O, Kesieme EB, Eluehike SU, Alufohai EF (2017) A FiveYear Review of Perforated Peptic Ulcer Disease in Irrua, Nigeria. Hindawi International Scholarly Research Notices.

6. Dohil R, Hassall E, Jevon G, Dimmick J (1999) Gastritis and gastropathy of childhood. $J$ Pediatr Gastroenterol Nutr 29: 378-394. [Crossref]

7. Richardson CT (1985) Pathogenetic factors in peptic ulcer disease. Am J Med 79: 1-7. [Crossref]

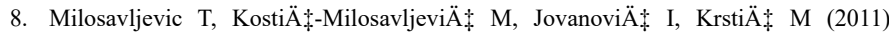
Complications of peptic ulcer disease. Dig Dis 29: 491-493. [Crossref]

9. Afuwape O, Irabor DO, Ayandipo O (2013) An Audit of Perforated Peptic Ulcer Disease in a Tropical Teaching Hospital. East and Central African Journal of Surgery 18: $40-44$.

10. Irabor DO (2005) An audit of peptic ulcer surgery in Ibadan, Nigeria. West Afr $J$ Med 24: 242-245. [Crossref]
11. Hardy JD, George R. Walker Jr GR, Conn JH (1961) Perforated Peptic Ulcer: An Analysis of 206 Consecutive Cases with Emphasis on Pathophysiologic Changes and Deaths. Annals of Surgery; 153(6): 911-930

12. Chalya PL, Mabula JB, Koy M, Mchembe MD, Jaka HM, et al. (2011) Clinical profile and outcome of surgical treatment of perforated peptic ulcers in Northwestern Tanzania: A tertiary hospital experience. World J of Emerg Surg 6:31 [Crossref]

13. Türkdogan MK, Hekim H, Tuncer I, Aksoy H (1999) The epidemiological and endoscopic aspects of peptic ulcer disease in Van region. East J of Med 4: 6-9.

14. Isenberg JI, McQuaid KR, Laine L, Rubin W (1991) Acid-peptic disorders. In Textbook of Gastroenterology. Edited by: Yamada T. J.B Lippincott comp, Philadelphia.

15. Elnagib E, Mahadi SE, Mohamed E, Ahmed ME (2008) Perforated peptic ulcer in Khartoum. Khartoum Med J 1: 62-64.

16. Khan SH, Aziz SA, Ul-Haq MI (2011) Perforated peptic ulcers: A review of 36 cases. Professional Med J 18: 124-127.

17. Mäkelä JT, Kiviniemi H, Ohtonen P, Laitinen SO (2002) Factors that predict morbidity and mortality in patients with perforated peptic ulcers. Eur J Surg 168: 446-451. [Crossref]

18. Montalvo-Javé EE, Corres-Sillas O, César Athié-Gutiérrez C (2011) Factors associated with postoperative complications and mortality in perforated peptic ulcer. Cir Cir 79: 128-135. [Crossref]

19. Bertleff MJ, Lange JF (2010) Perforated peptic ulcer disease: a review of history and treatment. Dig Surg 27: 161-169. [Crossref]

20. Ramakrishnan K, Salinas RC (2007) Peptic ulcer disease. Am Fam Physician 76: 1005 1012. [Crossref]

21. Sivri B (2004) Trends in peptic ulcer pharmacotherapy. Fundam Clin Pharmacol 18 23-31. [Crossref]

22. Etonyeaku AC, Agbakwuru EA, Akinkuolie AA, Omotola CA, Talabi AO, et al. (2013) A review of the management of perforated duodenal ulcers at a tertiary hospital in south western Nigeria. Afr Health Sci 13: 907-913. [Crossref]

23. Svanes C (2000) Trends in Perforated Peptic Ulcer: Incidence, Aetiology, Treatment and Prognosis. World J Surg 24: 277-283. [Crossref]

24. Dakubo JC, Naaeder SB, Clegg-Lamptey JN (2009) Gastro-duodenal peptic ulcer perforation. East Afr Med J 86: 100-109. [Crossref]

25. Gupta S, Kaushik R, Sharma R, Attri A (2005) The management of large perforations of duodenal ulcers. BMC Surg 5: 15. [Crossref]

26. Hill AG, Fracs MD (2001) Management of perforated duodenal ulcer. [Crossref]

27. Gisbert JP, Legido J, García-Sanz I, Pajares JM (2004) Helicobacter pylori and perforated peptic ulcer prevalence of the infection and role of non-steroidal antiinflammatory drugs. Dig Liver Dis 36: 116. [Crossref]

28. Rosenstock S, Jørgensen T, Bonnevie O, Andersen L (2003) Risk factors for peptic ulcer disease: a population based prospective cohort study comprising 2416 Danish adults. Gut 52:186-193. [Crossref]

29. Korman MG, Hansky J, Eaves ER, Schmidt GT (1983) Influence of cigarette smoking on healing and relapse in duodenal ulcer disease. Gastroenterology 85: 871-874. [Crossref]

30. Slade Howell H (2008) When repair is enough for perforated duodenal ulcer Contemporary Surgery 64: 521-524.

31. Ng EK, Chung SC, Sung JJ, Lam YH, Lee DW, et al. (1996) High Prevalence Helicobacter pylori Infection in Duodenal Perforations not caused by Non-Steroidal Anti- Inflammatory Drugs. Br J Surg 83: 1779-1781. [Crossref]

32. Jordan GL Jr, DeBakey ME, Duncan JM Jr (1974) Surgical management of perforated peptic ulcer. Ann Surg 179: 628-633. [Crossref]

33. Rayner HH (1930) Treatment of perforated peptic ulcer. Lancet 2: 107-108.

34. Sangster AH (1939) Perforated peptic ulcer: an analysis of 100 consecutive cases. Lancet 23: 1311-1313.

35. Berson HL (1942) Acute perforated peptic ulcers: an eighteen-year survey. Am J Surg 16: $385-394$.

36. Hastings N, Machida R (1961) Perforated peptic ulcer: results after simple surgical closure. Am J Surg 102: 136-142. [Crossref]

37. No authors listed (1989) Conservative management of perforated peptic ulcer. Lancet 2 : 1429-1430. [Crossref] 
38. Lagoo S, McMahon RL, Kakihara M, Pappas TN, Eubanks S (2002) The sixth decision regarding perforated duodenal ulcer. JSLS 6: 359-368. [Crossref]

39. Lunevicius R, Morkevicius M (2005) Management strategies, early results, benefits, and risk factors of laparoscopic repair of perforated peptic ulcer. World J Surg 29: 1299-1310. [Crossref]

40. Gutiérrez de la Peña C, Márquez R, Fakih F, Domínguez-Adame E, Medina J (2000) Simple closure or vagotomy and pyloroplasty for the treatment of a perforated duodenal ulcer: comparison of results. Dig Surg 17: 225-228. [Crossref]

41. Von Elm E, Altman DG, Egger M, Pocock SJ, Gøtzsche PC, et al. (2014) The Strengthening the Reporting of Observational Studies in Epidemiology (STROBE) Statement: guidelines for reporting observational studies. J Clin Epidemiol 61: 344 349. [Crossref]

42. Agha RA, Borrelli MR, Vella-Baldacchino M, Thavayogan R, Orgill DP (2017) The STROCSS Statement: Strengthening the Reporting of Cohort Studies in Surgery. Int $J$ Surg 46: 198-202. [Crossref]

43. Nuhu A, Madziga AG, Gali BM (2009) Acute perforated duodenal ulcer in Maiduguri: experience with simple closure and Helicobacter pylori eradication. West Afr J Med 28 : 384-387. [Crossref]

44. Nasio NA, Saidi H (2009) Perforated Peptic Ulcer Disease at Kenyatta National Hospital, Nairobi. East Cent Afr J Surg 14: 13-16.

45. Ersumo T, W/Meskel Y, Kotisso B (2005) Perforated peptic ulcer in Tikur Anbessa Hospital: a review of 74 cases. Ethiop Med J 43: 9-13. [Crossref]

46. Kang JY, Elders A, Majeed A, Maxwell JD, Bardhan KD (2006) Recent trends in hospital admissions and mortality rates for peptic ulcer in Scotland 1982-2002. Aliment Pharmacol Ther 24: 65-79. [Crossref]

47. Ugochukwu AI, Amu OC, Nzegwu MA, Dilibe UC (2013) Acute perforated peptic ulcer: on clinical experience in an urban tertiary hospital in south east Nigeria. Int $J$ Surg 11: 223-227. [Crossref]

48. Wegdam HH, Hillah AA (2013) Modified open omental plugging of peptic ulcer perforation in a municipal hospital in Ghana. $P M J G$.

49. Oribhabor FO, Adebayo BO, Aladesanmi T, Akinola DO (2013) Perforated duodenal Ulcer; Management in a resource poor, semi-urban Nigerian Hospital. Niger J Surg 19: 13. [Crossref]

50. Thorsen K, Glomsaker TB, vonMeer A, Søreide K, Søreide JA (2011) Trends in diagnosis and surgical management of patients with perforated peptic ulcer. $J$ Gastrointest Surg 15: 1329-1335. [Crossref]

51. Lee CW, Yip AW, Lam KH (1993) Pneumogastrogram in the diagnosis of perforated peptic ulcer. Aust N Z J Surg 63: 459-461. [Crossref]

52. Collier DS, Pain JA (1985) Non-steroidal anti-inflammatory drugs and peptic ulcer perforation. Gut 26: 359-363. [Crossref]

53. Ajao OG (1979) Perforated duodenal ulcer in a tropical African population. J Natl Med Assoc 71: 271-273. [Crossref]

54. Chen SC, Yen ZS, Wang HP, Lin FY, Hsu CY, et al. (2002) Ultrasonography is superior to plain radiography in the diagnosis of pneumoperitoneum. Br J Surg 89: 351-354. [Crossref]

55. Fedail SS, Araba BM, Homeda MM, Ghandour ZM (1983) Upper gastrointestinal endoscopy in Sudan: Analysis of 2500 endoscopies 2: 897-899. [Crossref]

56. Ohene-Yeboah M, Togbe B (2006) Perforated gastric and duodenal ulcers in an urban African population. West Afr J Med 25: 205-211. [Crossref]

57. Umerah BC, Singarayar J, Ramzan M, Kisumbi S (1978) Incidence of peptic ulcer in the Zambian African - a radiological study. Med J Zambia 12: 117-118. [Crossref]

58. Khalil AR, Yunas M, Qutbe AJ, Nisar W, Imran M (2010) Graham's omentopexy in closure of perforated duodenal ulcer. J Med Sci 18: 87-90.

59. Sharma SS, Manju RM, Sharma SM, Kulkarni H (2006) A prospective cohort study of postoperative complications in the management of perforated peptic ulcer. $B M C$ Surgery 6: 8. [Crossref]

60. Boey J, Choi KY, Alagaratnam TT, Poon A (1986) Risk stratification in perforated duodenal ulcers. A prospective validation of predictive factors. Ann Surg 205: 22-26. [Crossref]

61. Schein M, Saadia R, Decker GA (1986) Perforated peptic ulcer at the J. G. Strijdom Hospital: A retrospective study of 99 patients. $S$ Afr Med J 70: 21-23. [Crossref]

62. Mieny CJ, Kopelowitz W, Colsen P (1974) The management of perforated peptic ulcers. S Afr J Surg 12: 27-29. [Crossref]
63. Ekka NMP, Malua S (2016) Clinical study of peptic ulcer perforation in eastern India: An tertiary institution-based study. Int J Med Sci Pub Health 5: 2540-2544.

64. Schmitz EJ, Harkins HN, Olson HH, Moore HG Jr, Merendino KA (1953) Perforated peptic ulcer; a study of 136 cases in a county hospital. Ann Surg 138: 689-697. [Crossref]

65. Buck DL, Vester-Andersen M, Moller MH (2013) Danish clinical register of emergency surgery surgical delay is a critical determinant of survival in perforated peptic ulcer. $\mathrm{Br}$ J Surg 100: 1045-1049. [Crossref]

66. Moses JF, Hughes CD, Patel PB, Chao TE, Konneh SA, et al. (2015) Surgical outcomes for perforated peptic ulcer: A prospective case series at an academic hospital in Monrovia, Liberia. Afr J Emerg Med 5: 60-65.

67. Grimes CE, Bowman KG, Dodgion CM, Lavy CB (2011) Systematic review of barriers to surgical care in low-income and middle-income countries. World J Surg 35: 941-950. [Crossref]

68. Dye TD, Bogale S, Hobden C, Tilahun Y, Hechter V, et al. (2010) Complex care systems in developing countries: breast cancer patient navigation in Ethiopia. Cancer 116: 577-585. [Crossref]

69. Knowlton LM, Chackungal S, Dahn B, LeBrun D, Nickerson J, et al. (2013) Liberian surgical and anesthesia infrastructure: a survey of county hospitals. World $J$ Surg 37 : 721-729. [Crossref]

70. Kim JM, Jeong SH, Lee YJ, Park ST, Choi SK, et al. (2012) Analysis of risk factors for postoperative morbidity in perforated peptic ulcer. J Gastric Cancer 12: 26-35. [Crossref]

71. Koçer B, Sürmeli S, Solak C, Ünal B, Bozkurt B, et al. (2007) Factors affecting mortality and morbidity in patients with peptic ulcer perforation. $J$ Gastroenterol Hepatol 22: 565-570. [Crossref]

72. Kamani F, Mogimi M, Marashi SA, Peyrovi H, Sheikhvatan M (2010) Perforated peptic ulcer disease: mid-term outcome among Iranian population. Turk J Gastroenterol 21 125-128. [Crossref]

73. Arici C, Dinckan A, Erdogan O, Bozan H, Colak T (2002) Peptik ülser perforasyonu: Ameliyat mortalitesine etki eden risk faktörlerinin analizi. Ulusal Travma Derg 8: 142 146

74. Testini M, Portincasa P, Piccini G, Lissidini G, Pellegrini F, et al. (2003) Significant factors associated with fatal outcome in emergency open surgery for perforated peptic ulcer. World J Gastroenterol 9: 2338-2340. [Crossref]

75. Chan WH, Wong WK, Khin LW, Soo KC (2000) Adverse operative risk factors for perforated peptic ulcer. Ann Acad Med Singapore 29: 164-167. [Crossref]

76. Li CH, Chang WH, Shih SC, Lin SC, Bair MJ (2010) Perforated peptic ulcer in southeastern Taiwan. J Gastroenterol Hepatol 25: 1530-1536. [Crossref]

77. Lohsiriwat V, Prapasrivorakul S, Lohsiriwat D (2009) Perforated peptic ulcer: clinica presentation, surgical outcomes, and the accuracy of the Boey scoring system in predicting postoperative morbidity and mortality. World J Surg 33: 80-85. [Crossref]

78. Lee FY, Leung KL, Lai BS, Ng SS, Dexter S, et al. (2001) Predicting mortality and morbidity of patients operated on for perforated peptic ulcers. Arch Surg 136: 90-94. [Crossref]

79. Billing A, Fröhlich D, Schildberg FW (1994) Prediction of outcome us-ing the Mannheim peritonitis index in 2003 patients. Peritonitis Study Group. Br J Surg 81: 209-213. [Crossref]

80. Noguiera C, Silva AS, Santos JN, Silva AG, Ferreira J, et al. (2003) Perforated peptic ulcer: main factors of morbidity and mortality. World J Surg 27: 782-787. [Crossref]

81. Groen RS, Sriram VM, Kamara TB, Kushner AL, Blok L (2014) Individual and community perceptions of surgical care in Sierra Leone. Trop Med Int Health 19: 107116. [Crossref]

82. Kuremu RT (2002) Surgical management of peptic ulcer disease. East Afr Med J 79: 454-456. [Crossref]

83. Amela S, Serif B, Lidija L (2006) Early radiological diagnostics of gastrointestinal infection in the management of peptic ulcer perforation. Radiol Oncol 40: 67-72.

84. Cellan-Jones CJ (1929) A rapid method of treatment in perforated duodenal ulcer. $\mathrm{Br}$ Med J 1: 1076-1077. [Crossref]

85. Graham RR (1937) The treatment of perforated du-odenal ulcers. Surg Gynecol Obstet 5: $235-238$. 
86. Fallat ME, White MJ, Richardson JD, Flint LM (1983) Reassessment of Graham-Steele closure in acute perforated peptic ulcer. South Med J 76: 1222-1224. [Crossref]

87. Schein M (2005) Perforated peptic ulcer: Schein's Common Sense Emergency Abdominal Surgery. Part III, Berlin.

88. Mikulicz J (1885) Ueber Laparotomiebei Magen und Darmperforation. Samml Klin Vort Leipzig 262: 2307.

89. Munro WS, Bajwa F, D Menzies D (1996) Laparoscopic repair of perforated duodenal ulcers with a falciform ligament patch. Ann R Coll Surg Engl 78: 390-391. [Crossref]

90. Ibrahim AMS, Arunkumar A (2017) Comparison of Surgical Techniques for Gastro Duodenal Perforation Closure: A Prospective Study of Falciform ligament Patch Versus Graham Omental Patch. J Dent Med Sci 16: 44-50.

91. Fry DE, Richardson JD, Flint LM Jr (1978) Closure of an acute perforated peptic ulcer with the falciform ligament. Arch Surg 113: 1209-1210. [Crossref]
92. Varcuş F, Lazăr F, Beuran M, Lica I, Turculeț C, et al. (2013) Laparoscopic treatment of perforated duodenal ulcer-a multicenter study. Chirurgia Bucur 108: 172-176. [Crossref]

93. Sneider EB, Cahan MA, Litwin DE (2010) Laparoscopic repair of acute surgical diseases in the 21st century. Minerva Chir 65: 275-296. [Crossref]

94. Joshi AH, Vyas PH, Jayswal J (2016) Role of laparoscopic surgery for management of duodenal ulcer perforation. Int J Med Sci Public Health 5: 807-809.

95. Bae S, Shim KN, Kim N, Kang JM, Kim DS, et al. (2012) Incidence and shortterm mortality from perforated peptic ulcer in Korea: a population-based study. $J$ Epidemiol 22: 508-516. [Crossref]

96. Rijnhart-De Jong HG, Draaisma WA, Smout AJ, Broeders IA, Gooszen HG (2008) The Visick score: a good measure for the overall effect of antireflux surgery? Scand $J$ Gastroenterol 43: 787-793. [Crossref]

Copyright: $@ 2019$ Alegbeleye BJ. This is an open-access article distributed under the terms of the Creative Commons Attribution License, which permits unrestricted use, distribution, and reproduction in any medium, provided the original author and source are credited. 